\title{
Run-Away Energetic Reactions in the Exhaust of Deposition Reactors
}

\author{
Yen-Hsun Chang ${ }^{1}$, Jivaan Kishore ${ }^{2}$, Farhang Shadman ${ }^{1}$ \\ ${ }^{1}$ Chemical Engineering Department, University of Arizona, Tucson, Arizona, USA \\ ${ }^{2}$ Micron Technology Inc., Boise, Idaho, USA \\ Email: yenhsunc@email.arizona.edu
}

How to cite this paper: Chang, Y.-H., Kishore, J. and Shadman, F. (2019) Run-Away Energetic Reactions in the Exhaust of Deposition Reactors. Advances in Chemical Engineering and Science, 9, 223-238. https://doi.org/10.4236/aces.2019.92017

Received: March 25, 2019

Accepted: April 27, 2019

Published: April 30, 2019

Copyright (c) 2019 by author(s) and Scientific Research Publishing Inc. This work is licensed under the Creative Commons Attribution International License (CC BY 4.0).

http://creativecommons.org/licenses/by/4.0/

\section{cc) (i) Open Access}

\begin{abstract}
A model is developed to simulate the processes that may cause run-away exothermic reactions in the downstream of typical deposition reactors used in semiconductor manufacturing. This process model takes into account various modes of mass and heat transport as well as chemical reactions and provides insight into the key mechanisms that trigger the uncontrolled energetic reactions and cause the formation of potentially damaging hotspots. Using the developed model, a parametric study was conducted to analyze the effects of various system and operating conditions. In particular, the effects of the gaseous reactants concentrations and incoming temperature, the extent of accumulation of deposits, and the gas flow rate, and the reactions activation energy and heat of reaction are analyzed and the location and time of hot spot formation for each case are determined. The results are useful in developing strategies for mitigating the occurrence of the damaging energetic events.
\end{abstract}

\section{Keywords}

Energetic Events, Energetic Material, Process Stimulation Model

\section{Introduction}

Chemical vapor deposition and atomic layer deposition processes continue to play a key role in the semiconductor industry [1]. One of the prevalent but sporadic issues associated with the CVD systems is the formation and accumulation of deposits on various surfaces downstream of the tools (exhaust, pumps, and other components). These deposits come from three main sources: 1) the unreacted portion of precursors that are used in the deposition process, especially in an atomic layer deposition (ALD) process [2], 2) the by-products of the reactions in the deposition tool, and 3) the mixing and reactions when exhaust from 
various tools shares the same exhaust line. The accumulation of these deposits is sometimes followed by a rapid surge of uncontrolled reactions in the exhaust system. In addition to causing process interruption, these energetic reactions often damage the exhaust components and generate hazardous compounds. Despite documented occurrence and impact of these incidents, the underlying conditions and causes are not clearly understood, primarily due to the difficulty of sampling and analyzing the culprit reactants and the limitation of any direct dynamic measurements at the time of occurrence. Another intrinsic limitation of the experimental approach at this time is the wide range of chemistries and system/exhaust configurations in different fabs.

The materials causing these reactions are substances, such as organic and organometallic precursors, which contain organic ligands or carbon-metal bonds that are unstable and highly reactive [2] [3]. The growing use of these deposition techniques has expanded the number of precursor materials for device fabrication. The highly reactive nature of such precursors presents a challenge when the unreacted precursors are transported downstream of the reactor and into the exhaust system, where they form deposits on the exhaust piping, react with other chemicals, and generate potentially hazardous secondary by-products [4]. At least 70 run-away reaction events, involving these energetic materials, have been reported [5] [6] [7]. The majority of these events are associated with the reactions of deposited materials in the frontline or downstream of atomic layer deposition (ALD) and chemical vapor deposition (CVD) process tools.

While substantial improvement in mitigating downstream accumulation on exhaust lines and internal pump components has been made using in-line devices such as hot and cold traps and gas reaction columns, the downtime necessary to change expended components causes detrimental process interruption. Additionally, point-of-use abatement can become costly when used with every processing tool. In order to mitigate the detrimental effects of downstream deposition and prevent disastrous results of thermal run-away, it is necessary to gain a fundamental understanding of the chemical processes taking place and further determine how these processes respond to changes in processing conditions [8]. The methods of thermodynamic assessment have been demonstrated as useful tools in estimating the ranges for the desirable and undesirable reaction products [9]. Further kinetic and mechanistic studies of the deposition process are needed to gain insight into the dynamics of the run-away reactions.

The long-term goal of this study is to explore the fundamentals of these energetic events through comprehensive process simulation, mapping a wide range of chemistries and process conditions, understanding the mechanism of the harmful energetic reactions, and identifying the key factors in controlling the process. In this respect, the process model is valuable for the analysis of data, determination of key operational parameters, and most importantly, developing strategies and methods for preventing the run-away reactions. 


\section{Method Approach}

The generalized pathway and mechanism of the energetic reactions are illustrated in Figure 1.

The unreacted precursors and the reactive by-products exiting the process tool (depicted as generic A and B) go through a number of transformations in the exhaust system before being effectively removed or treated by various abatement methods. A portion of these compounds is deposited on the surfaces of the exhaust lines by either physisorption or more energetic chemisorption. The combined overall deposition process is shown as $\mathrm{B} \rightarrow \mathrm{B}_{\mathrm{s}}$. In general, the deposit continues to react with other components in the gas phase in a heterogeneous reaction that produces other by-products and releases the heat of reaction $(\Delta \mathrm{H})$. This is shown as $\mathrm{A}+\mathrm{bB}_{\mathrm{s}} \rightarrow \operatorname{Prod}+$ Heat $(\Delta \mathrm{H})$. The heat of reaction is partly transferred to the gas phase and transported downstream primarily by convection. It is speculated that in most cases, due to the relatively slow gas-solid interphase heat transfer, most of this heat remains in the solid phase, causing a gradual increase in the temperature of the deposit.

A schematic of the exhaust piping is shown in Figure 2. The distribution of the deposited material is generally not uniform and goes through a peak at some location downstream of the tool in the exhaust line. The shape of this distribution depends on the reactor and its operating conditions. In this study, the following adjustable equation, Equation (1), was included in the model that can be used in representing a variety of conditions.

$$
C_{b 0}=C_{b 0 \max } z(L-z) /(\mathrm{mL}) z=0 \text { to } L
$$

where $C_{b 0}$ is the initial concentration of the deposited material along the model geometry, $C_{b 0 \max }$ is peak initial concentration at location $z, z$ is the distance along the pipe, $L$ is the length of the pipe, and $\mathrm{m}$ is an adjustment parameter for changing the shape of the $C_{b 0}$ concentration profile.

To analyze the dynamics of the transport and reactions that take place in the pipe, conservation equations for the mass and energy are formulated. These balances are shown in Equations (2)-(5). In these equations, subscript " $A$ " stands for the gaseous reactant and " $B$ " for the deposited reactant. The subscript " $g$ " and " $\mathrm{s}$ " generally refer to the gas and solid phases, respectively.

The mass balance equation of gas reactant, Equation (2), includes convection, dispersion, reaction, and accumulation terms. The inlet and the outlet boundary conditions are at $z=0$ and $z=L$, respectively. " $D_{e}$ ” is the dispersion coefficient, " $u_{0}$ " is the gas flow rate, and " $d$ " is diameter of the pipeline. The heat balance (Equation (3)) includes convection, dispersion, heat transfer between the two phases, and accumulation. " $\rho_{\mathrm{g}}$ " is the density of gas phase and " $\lambda_{e}$ " is thermal conductivity. The heat balance in the solid phase (Equation (5)) includes accumulation, heat generation by the reaction, heat transfer from the solid phase to the gas phase, and the heat transfer to the surrounding through the pipe wall. " $h_{0}$ " and " $h_{a}$ " are the heat transfer coefficients and " $T_{a}$ ” is the surrounding temperature. 


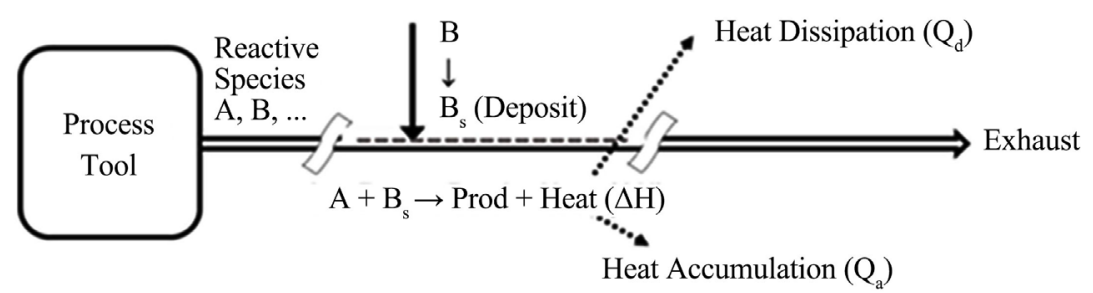

Figure 1. Illustration of the energetic reactions pathway in the exhaust of a generic deposition reactor.

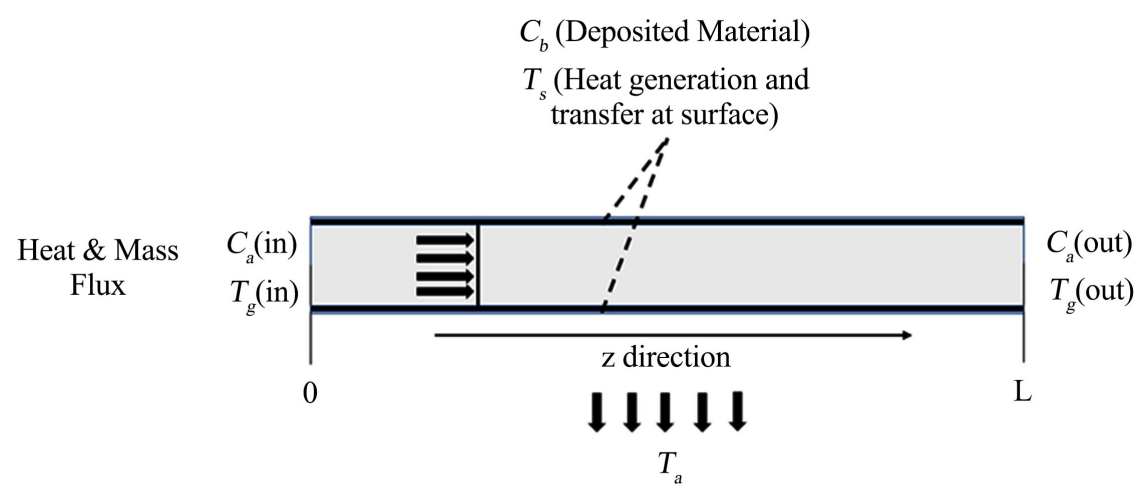

Heat transfer to outside air

Figure 2. Process components and configuration in a generic exhaust pipe.

$$
\begin{gathered}
\frac{\partial C_{a}}{\partial t}-D_{e} \frac{\partial^{2} C_{a}}{\partial z^{2}}+u_{0} \frac{\partial C_{a}}{\partial z}=-\frac{1}{b} \frac{4}{d} k C_{a} C_{b} \\
\rho_{g} C_{p g} \frac{\partial T_{g}}{\partial t}-\lambda_{e} \frac{\partial^{2} T_{g}}{\partial z^{2}}+u_{0} \rho_{g} C_{p g} \frac{\partial T_{g}}{\partial z}=h_{0}\left(T_{g}-T_{s}\right) \\
\frac{\partial C_{b}}{\partial t}=-k C_{a} C_{b} \\
\rho_{s} C_{p s} \frac{\partial T_{s}}{\partial t}=(-\Delta H) k C_{a} C_{b}-h_{0}\left(T_{s}-T_{g}\right)-h_{a}\left(T_{s}-T_{a}\right)
\end{gathered}
$$

The rate coefficient, $k$, is given by the following equation:

$$
k=k_{0} \exp \left(-\frac{E}{R T_{s}}\right)
$$

The concentration boundary and initial conditions for the gas and the solid phases are given by the following equations:

$$
\begin{gathered}
z=0\left(-D_{e} \frac{\partial^{2} C_{a}}{\partial z^{2}}+u_{0} C_{a}\right)_{Z=0}=u_{0} C_{a 0} \\
z=L \frac{\partial C_{a}}{\partial z}=0 \\
t=0 C_{a}=C_{a 0} \\
t=0 C_{b 0}=C_{b 0 \max } z(L-z) / \mathrm{mL}
\end{gathered}
$$

Similarly, the temperature boundary and initial conditions for the gas and 
solid phases are given by the following equations:

$$
\begin{gathered}
z=0 T_{g}=T_{g 0} \\
z=L \frac{\partial T_{g}}{\partial z}=0 \\
t=0 T_{g}=T_{g 0} \\
t=0 T_{s}=T_{s 0}
\end{gathered}
$$

\section{Results and Discussion}

\subsection{Parametric Study}

The process model was used in a parametric study to understand the effects of various system and operating conditions on the mechanism and dynamics of the energetic events. In particular, six parameters were studied: concentration of the gaseous reactant, concentration of the deposit, velocity of the carrier gas, inlet temperature, reaction enthalpy, and reaction activation energy. Only one parameter is varied over a selected range at a time to isolate and determine its effect on the overall process. The base values and the ranges of variation these parameters in this parametric study are shown in Table 1.

Figure 3 shows the effect of $C_{b 0}$ on the size and the location of the peak temperatures in the gas and the solid phases. The results show how the peaks in the gas and solid temperatures increase with the increase in the concentration of the deposited material. The locations of the gas and solid hot spots (the location of the highest temperatures in these phases) move downstream with the increase in $C_{b 0}$, primarily due to a larger heat accumulation.

The effect of $C_{a 0}$ on the process is shown in Figure 4. The resulting effects on the size and the location of the peak temperatures are similar to those of $C_{b 0}$.

The effect of flow rate on the peak temperatures is shown in Figure 5. The results show that the temperatures in both the solid and the gas phases decrease with the increase in the flow rate. The deposit removal rate does not increase significantly by increasing the flow rate. This is because the increase in flow rate causes an increase in the heat transfer coefficients and a more efficient heat dissipation [2] [10]; this lowers the heat accumulation and reaction rate. The hot spot for the gas phase moves towards the pipe outlet as flow rate increases, indicating the dominance of convection in accumulation of heat in the gas phase. In general, flow rate has a large effect on the location of the hot spots; it can be effectively utilized to lower the size of the hotspot and move its location away from the sensitive parts of the exhaust system.

The effect of the incoming gas temperature is shown in Figure 6 and Figure 7. The results show that the hot spot location shifts towards the inlet section of the exhaust pipe as the incoming gas temperature increases. This is expected due to a higher reaction rate close to the inlet of the exhaust and a lower heat accumulation towards the outlet. Both of these trends are potentially damaging to the process tool and the sensitive equipment and should be avoided. 

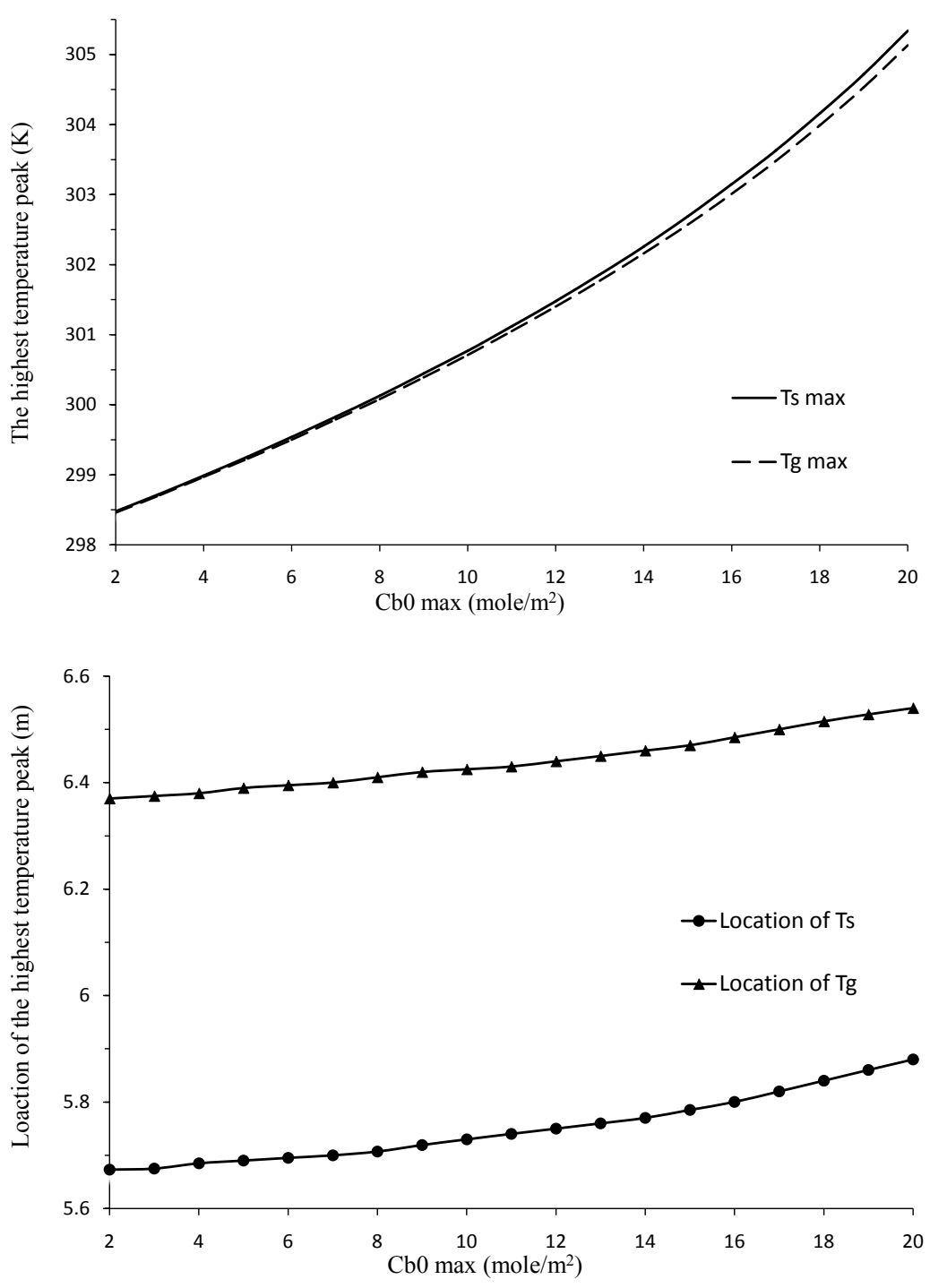

Figure 3. Effect of $C_{b 0}$ on the size and the location of the peak temperatures in the gas and solid phases.

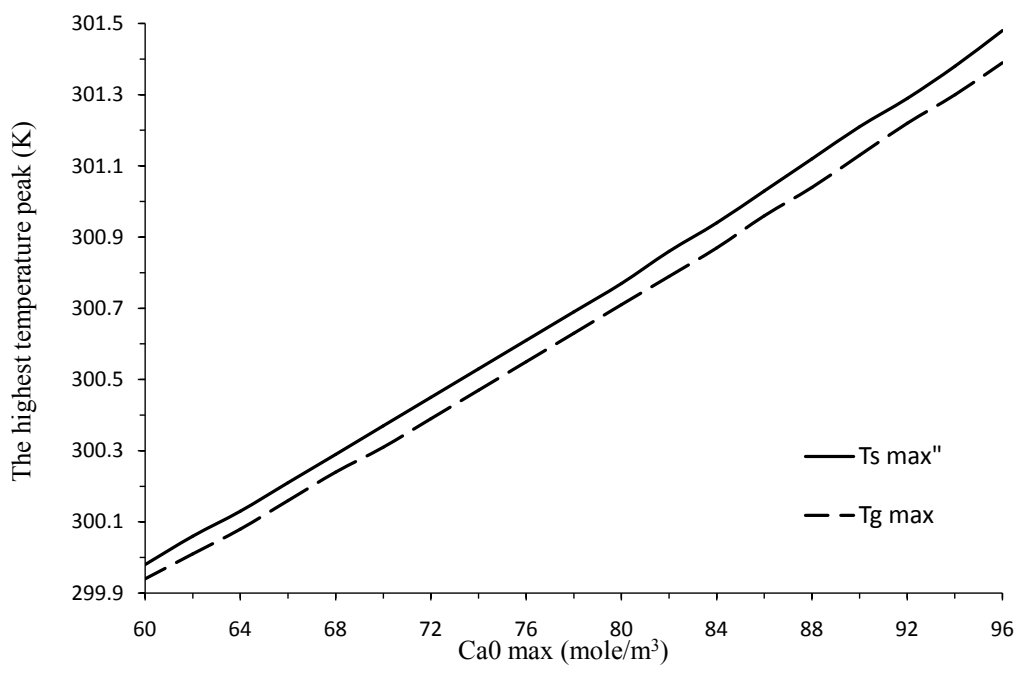




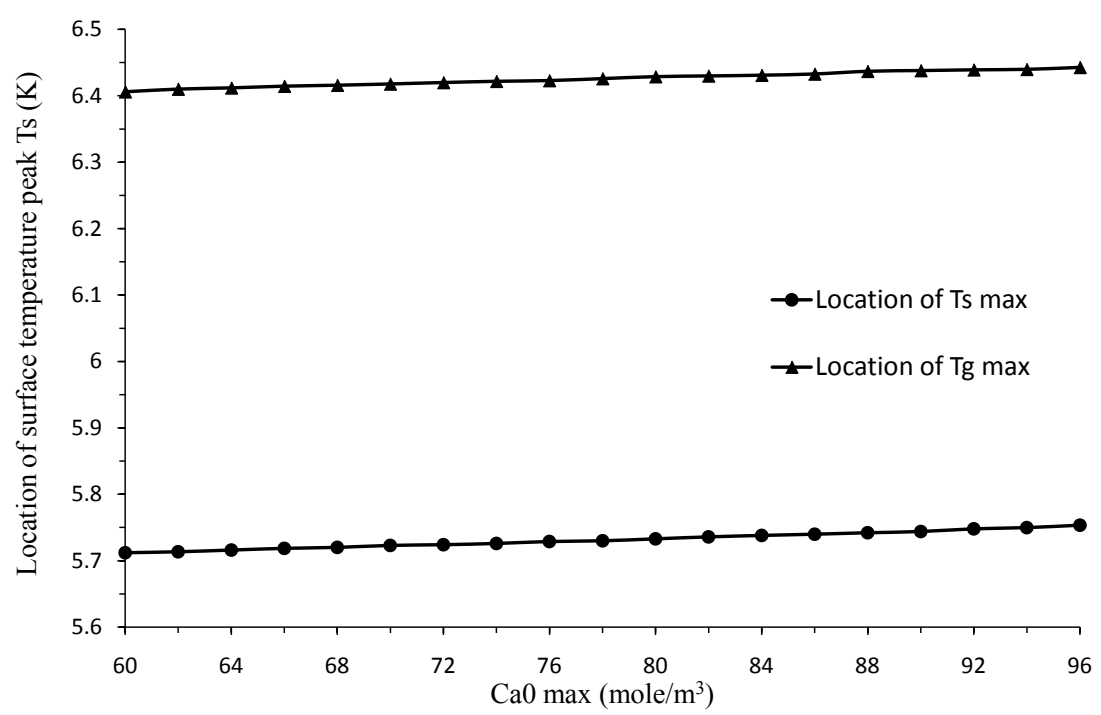

Figure 4. Effect of $C_{a 0}$ on the size and the location of the peak temperatures in the gas and solid phases.
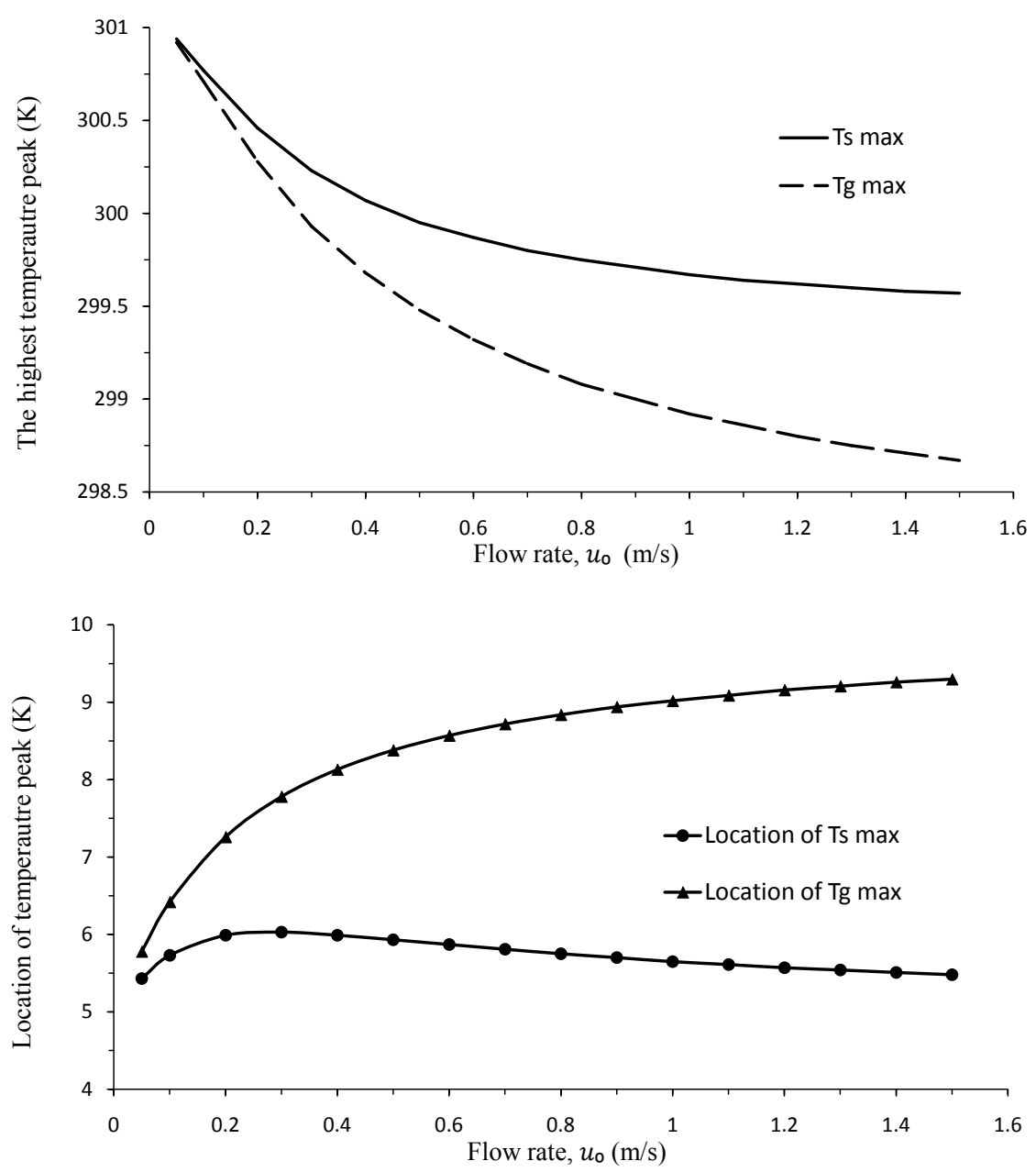

Figure 5. Effect of flow rate on the size and the location of the peak temperatures in the gas and solid phases. 
Line Graph: (K)

1
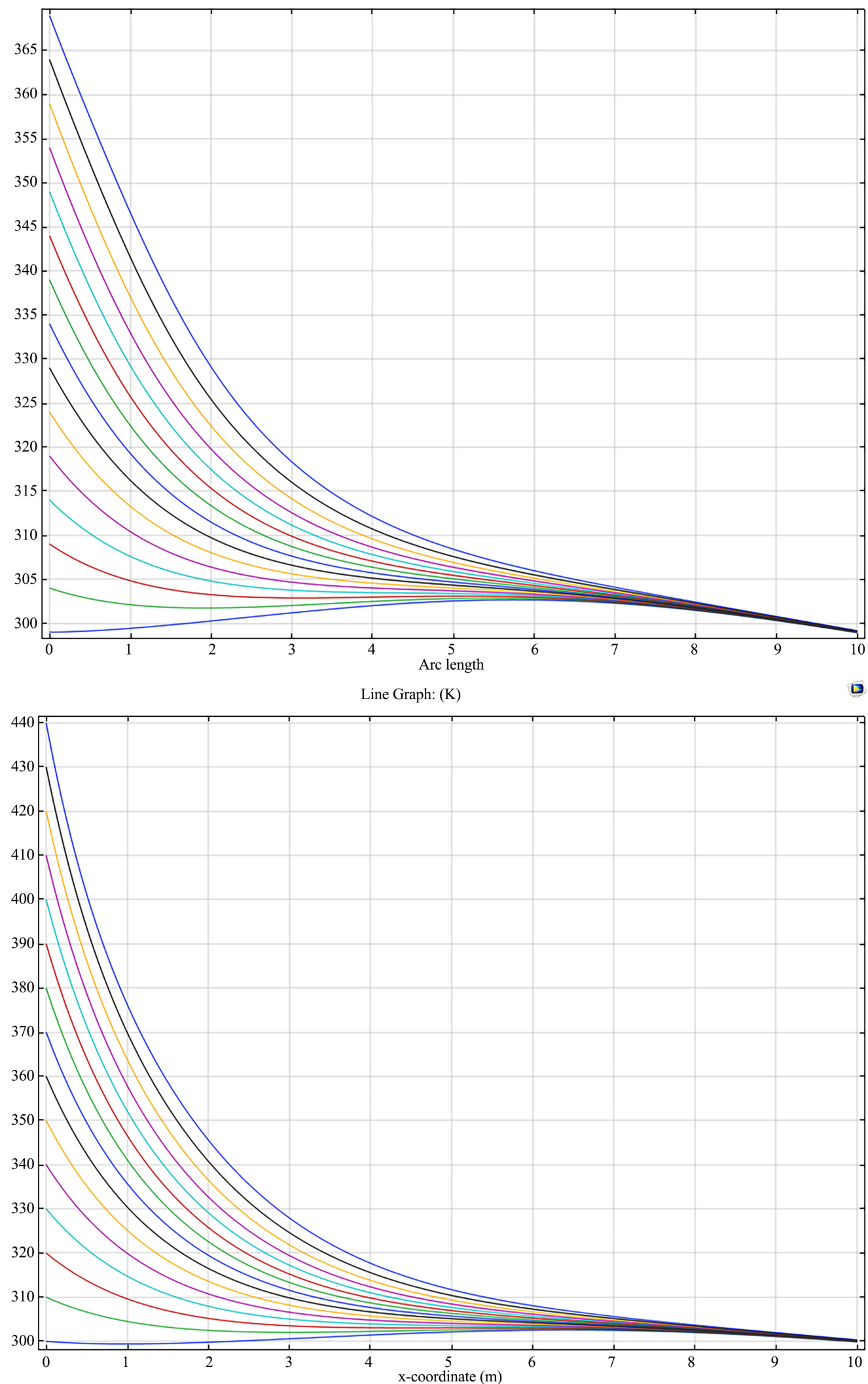

Figure 6. Effect of the inlet temperature on the size and the location of the peak temperatures in the gas and solid phases. 


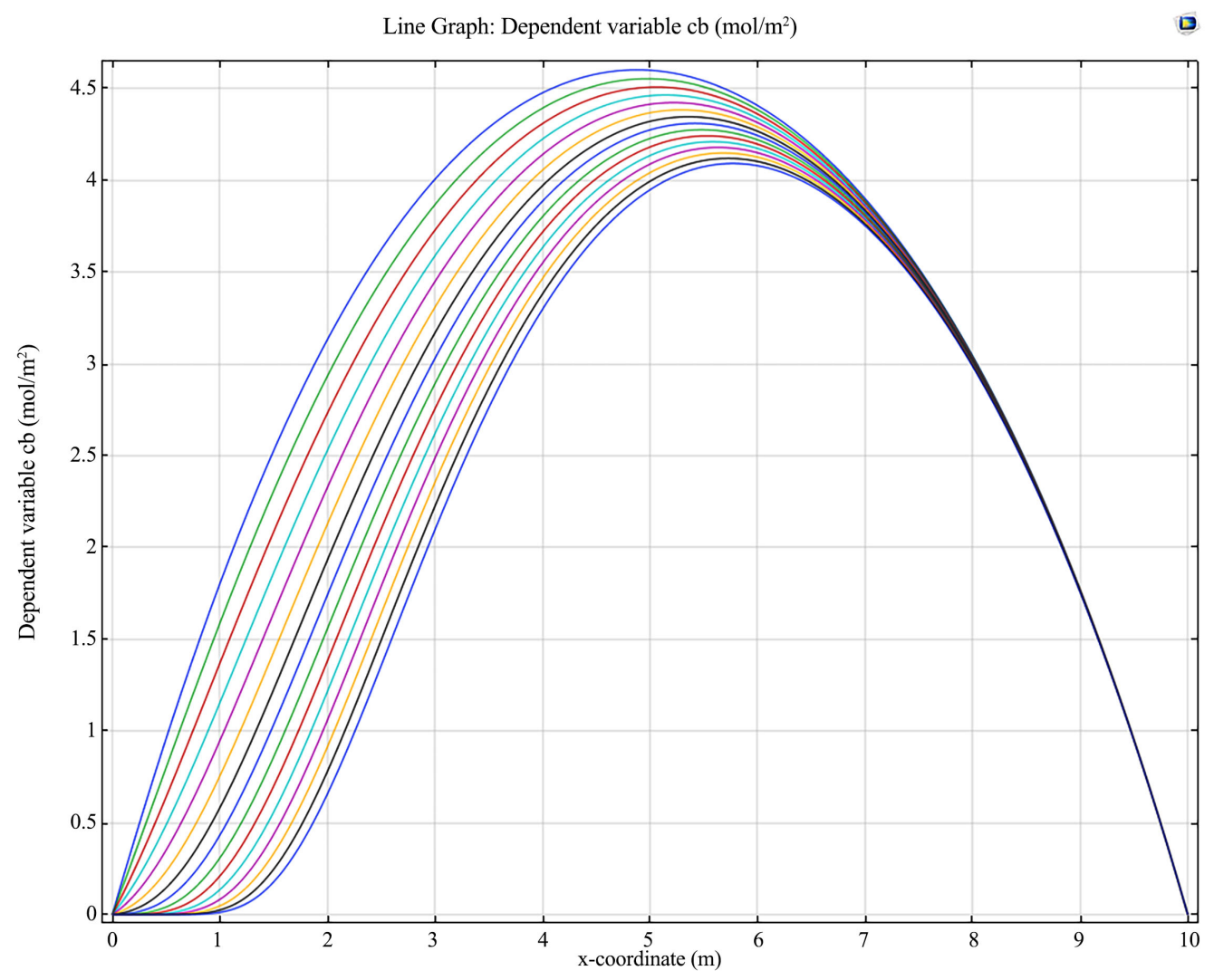

Figure 7. The Effect of the inlet temperature on the deposit profile and its removal.

Table 1 . The base value and the variation range of parameters in the sensitivity analysis.

\begin{tabular}{|c|c|c|c|}
\hline Parameter & Unit & Base Value & Parametric Study Range \\
\hline$C_{b 0 \max }$ & $\mathrm{mole} / \mathrm{m}^{2}$ & 10 & 2 to 20 \\
\hline$C_{a}$ & $\mathrm{~mole} / \mathrm{m}^{3}$ & 80 & 60 to 96 \\
\hline$u_{0}$ & $\mathrm{~m} / \mathrm{s}$ & 0.1 & 0.05 to 1.5 \\
\hline$T_{g 0}$ & K & 298 & 300 to 440 \\
\hline$\Delta H$ & $\mathrm{~kJ} / \mathrm{mole}$ & -1250 & -750 to -1700 \\
\hline$E$ & $\mathrm{~kJ} / \mathrm{mole}$ & 50 & 47.5 to 57 \\
\hline$C_{p g}$ & $\mathrm{~J} / \mathrm{mole} \cdot \mathrm{K}$ & 30 & - \\
\hline$C_{p s}$ & $\mathrm{~J} /$ mole $\cdot \mathrm{K}$ & 25 & - \\
\hline$D e$ & $\mathrm{~m}^{2} / \mathrm{s}$ & $2 \times 10^{-9}$ & - \\
\hline$d$ & $\mathrm{~m}$ & 0.3 & - \\
\hline$h_{0}$ & $\mathrm{~J} / \mathrm{m}^{2} \cdot \mathrm{s} \cdot \mathrm{K}$ & 12.5 & - \\
\hline$k_{0}$ & $\mathrm{~m}^{3} / \mathrm{s} \cdot \mathrm{mole}$ & 18 & - \\
\hline$L$ & $\mathrm{~m}$ & 10 & - \\
\hline$\rho_{g}$ & $\mathrm{~mole} / \mathrm{m}^{3}$ & 40 & - \\
\hline$\rho_{s}$ & $\mathrm{~mole} / \mathrm{m}^{3}$ & $3 \times 105$ & - \\
\hline$T_{a}$ & $\mathrm{~K}$ & 298 & - \\
\hline$T_{s 0}$ & $\mathrm{~K}$ & 298 & - \\
\hline
\end{tabular}


The effect of the incoming gas temperature is shown in Figure 6 and Figure 7. The results show that the hot spot location shifts towards the inlet section of the exhaust pipe as the incoming gas temperature increases. This is expected due to a higher reaction rate close to the inlet of the exhaust and a lower heat accumulation towards the outlet. Both of these trends are potentially damaging to the process tool and the sensitive equipment and should be avoided.

The effect of the heat of reaction (enthalpy change) and the activation energy are shown in Figure 8 and Figure 9. While the hot spot size increases mildly with the heat of reaction, the peak size is more sensitive to the reaction rate than to the enthalpy change. This is due to the dominant effect of the process dynamics and kinetic properties as opposed to that of equilibrium and thermodynamic properties. This is further confirmed by the results of the parametric study, shown in Figure 9. The effect of the activation energy is far more significant than that of heat of reaction due to its primary and large impact on the reaction rate and process dynamics.

\subsection{Onset of the Run-Away Reactions}

As seen in the previous section, the reactions in the exhaust system generally cause the formation of a peak in the temperature of the gas and/or solid phases. In most cases, this peak temperature rises first and then falls as the reaction depletes the deposited reactants on the pipe; consequently, in most cases, the process proceeds without causing any damage to the system. However, under certain conditions, the rise in temperature is too rapid and too large for the system to tolerate and handle safely. Under these conditions, the process exhibits a rapid change in its dynamics that is similar to ignition in the combustion systems. It is very important to determine the conditions that produce this critical situation and make sure that the operating conditions are selected to stay safely far from this run-away ignition.

In this section, some examples are presented to show how the process simulator can be used to determine the safe range of operation and the critical ignition value for a system parameter. Results in Figure 10 show the critical value of the deposit peak, $C_{b 0 \max }$, while the other parameters are kept at their base values. As shown in Figure 10(a) and Figure 10(b), the critical value for this peak deposit concentration is about $28 \mathrm{~mole} / \mathrm{m}^{2}$. When this concentration is at $27.9 \mathrm{~mole} / \mathrm{m}^{2}$, the temperature peak rises first; but then, after 21 minutes, it begins to fall due to depletion of the solid reactant. However, at a slightly higher value of $C_{b 0 \max },(28$ mole $/ \mathrm{m}^{2}$ ), the temperature rise accelerates rapidly after 20 minutes; at $21 \mathrm{mi}$ nutes, it reaches about 60 degrees higher than the values corresponding to $C_{b 0 \max }$ $=27.9$. The temperature profiles predicted by the process model after the onset of the runaway reactions are not practically relevant since under those conditions, the physical integrity of the system is compromised, and the system is irreversibly damaged.

Applying the same methodology, the process simulator can be used to determine the onset of the run-away reaction and the critical values of the operational 
parameters. The results for the heat of reaction are shown in Figure 11(a) and Figure 11(b). Similar results are observed for inlet gaseous concentration, flow rate, and activation energy. The critical values and the time for the onset of the run-away reaction for each case are summarized in Table 2 .
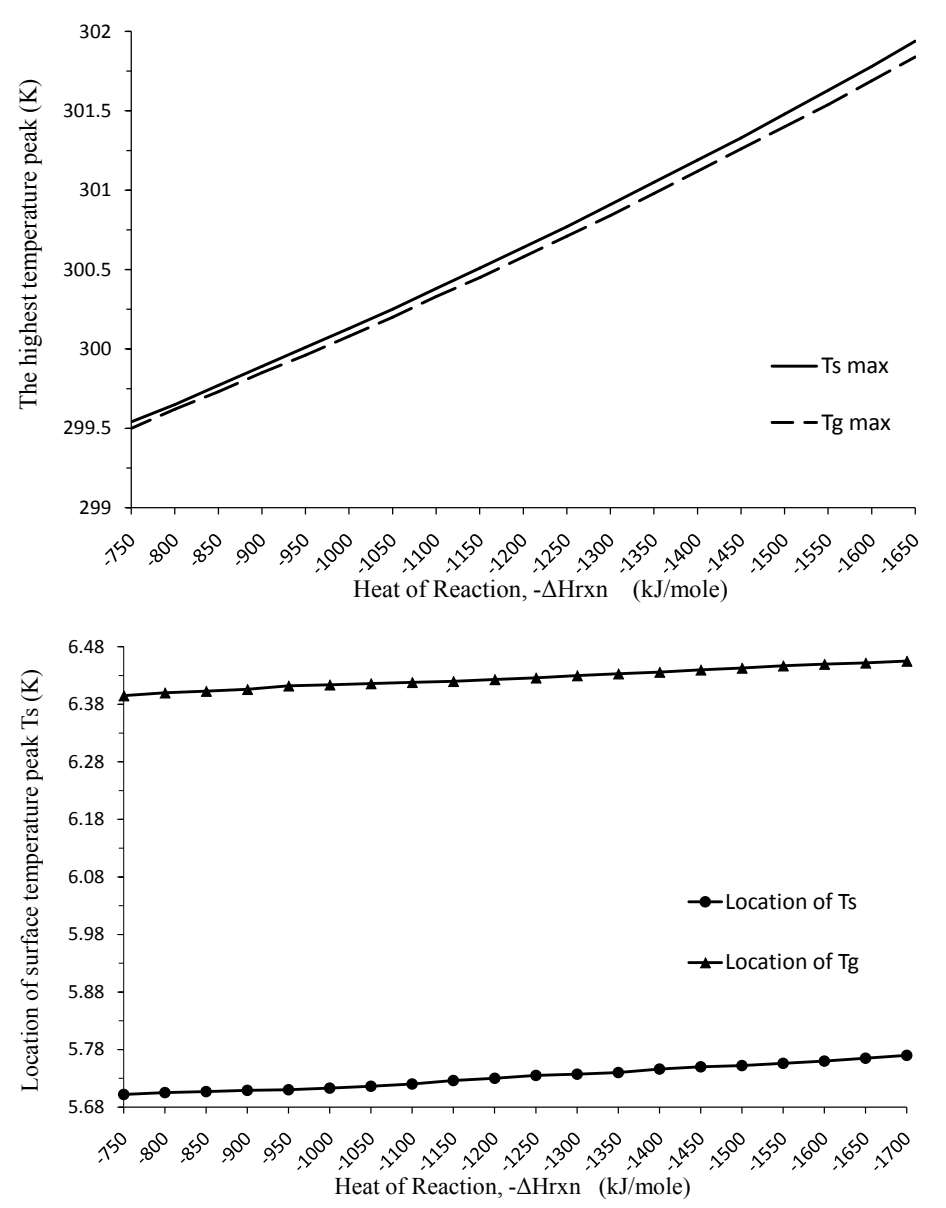

Figure 8. Effect of heat of reaction on the size and the location of the peak temperatures in the gas and solid phases.

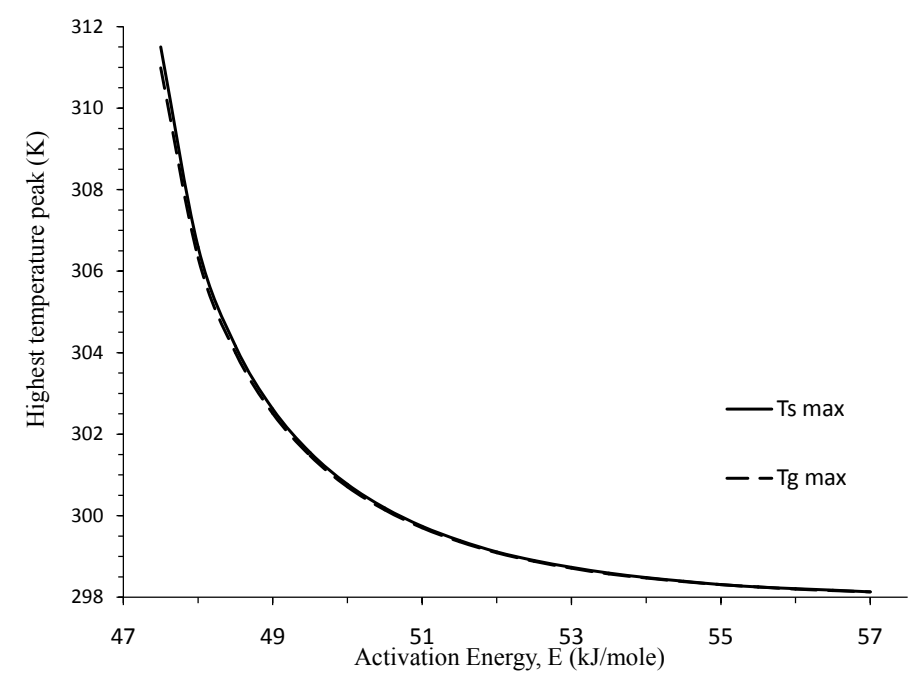




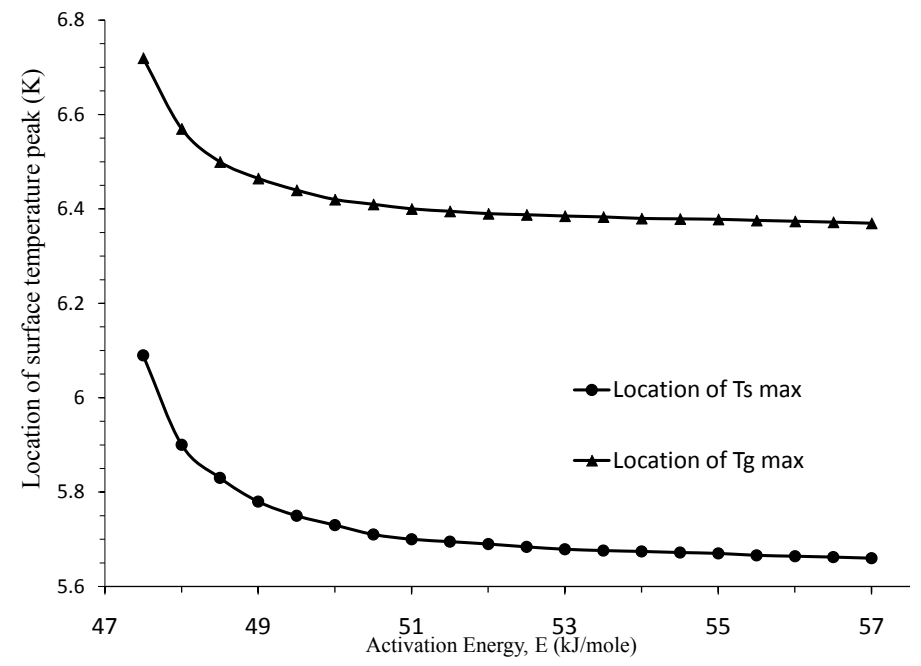

Figure 9. Effect of activation energy on the size and the location of the peak temperatures in the gas and solid phases.

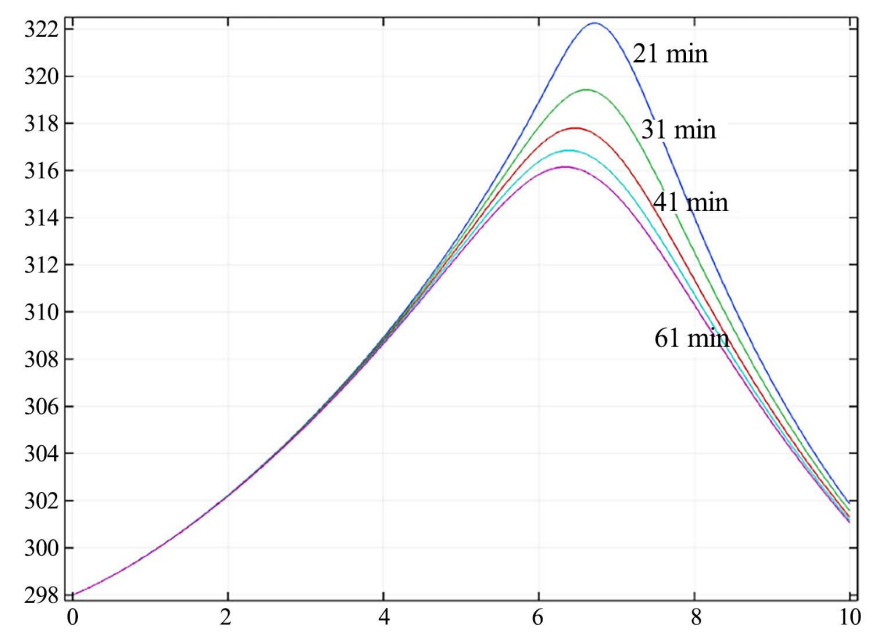

(a)

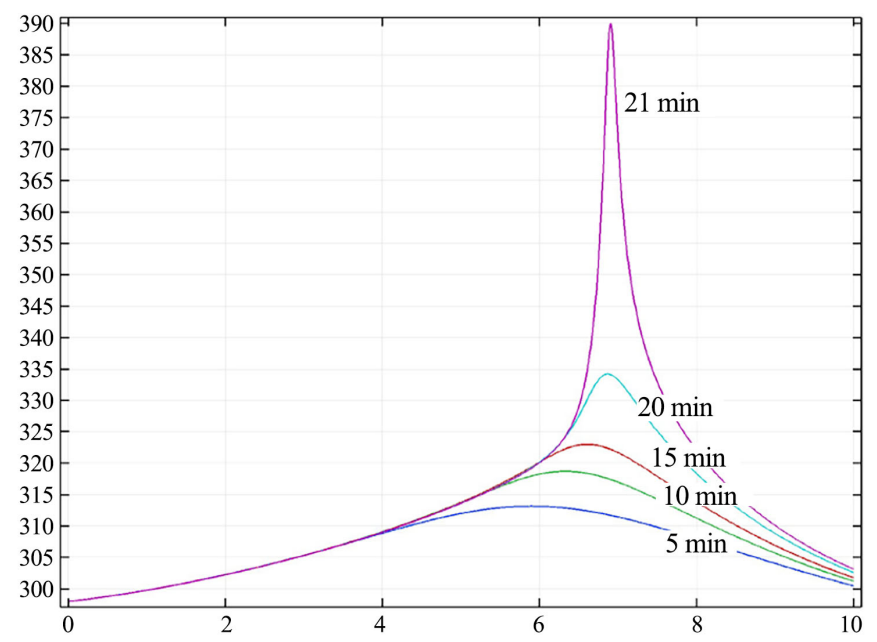

(b)

Figure 10. The solid phase temperature profiles for two values of $C_{b 0 \max }: 27.9 \mathrm{moles} / \mathrm{m}^{2}$ in (a), and $28 \mathrm{moles} / \mathrm{m}^{2}$ in (b). 


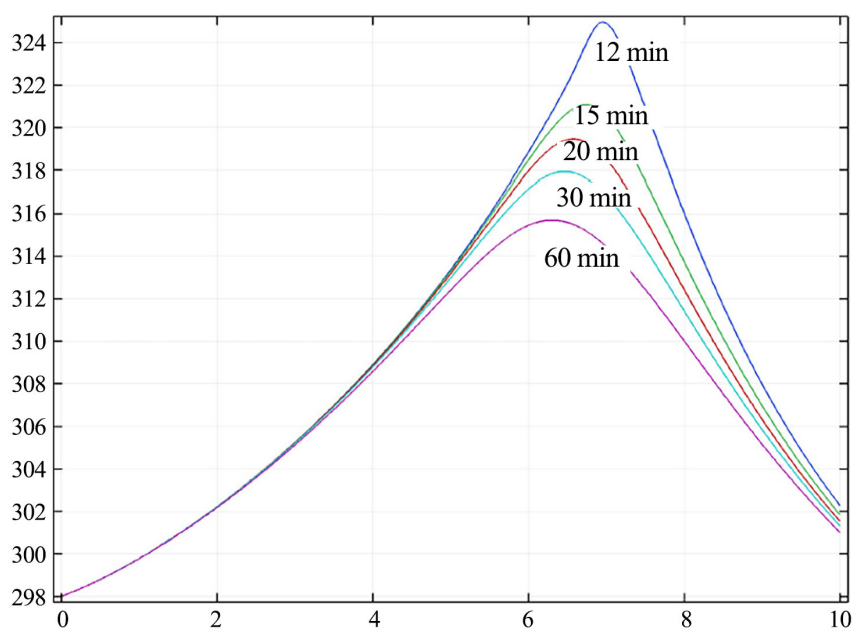

(a)

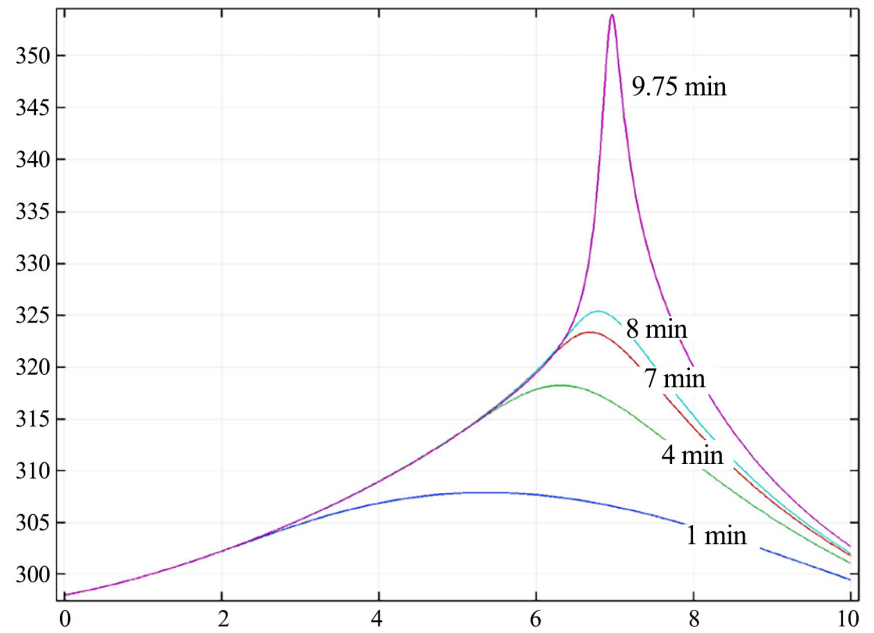

(b)

Figure 11. The solid phase temperature profiles for two values of heat of reaction: 3479 $\mathrm{kJ} / \mathrm{mole}$ in (a) and $3480 \mathrm{~kJ} / \mathrm{mole}$ in (b).

Table 2. The critical values of selected parameters at the onset of run-away reaction.

\begin{tabular}{cccc}
\hline Parameter & Unit & Critical Value & Ignition Time \\
\hline$C_{b 0 \max }$ & mole $/ \mathrm{m}^{2}$ & 28 & $21 \mathrm{~min} 6 \mathrm{sec}$ \\
$C_{a}$ & $\mathrm{~mole} / \mathrm{m}^{3}$ & 223.5 & $10 \mathrm{~min} 17 \mathrm{sec}$ \\
$\Delta H$ & $\mathrm{~kJ} / \mathrm{mole}$ & 3480 & $9 \min 51 \mathrm{sec}$ \\
$E$ & $\mathrm{~kJ} / \mathrm{mole}$ & 47.3 & $7 \mathrm{~min} 19 \mathrm{sec}$ \\
$u_{0}$ & $\mathrm{~m} / \mathrm{s}$ & \multicolumn{2}{c}{ No runaway reaction occurred } \\
\hline
\end{tabular}

\section{Summary and Conclusions}

The dynamics of run-away energetic reactions and the formation of hot-spots, involving reactive deposits in the downstream of ALD and CVD deposition tools, have been analyzed. A process model is developed to show the interactions of transport processes and reactions that lead to these energetic events. The 
process simulation includes convective and diffusive modes of mass transfer in the gas phase, heterogeneous reactions between the gas phase reactants and reactive deposits on the walls, and various modes of heat transfer between the two phases and to the surrounding air. The results show that, in general, hot spots (peaks in the gas and solid temperatures) are formed at some locations in the exhaust pipe because of the accumulation of heat and its transport downstream. These hot spots typically move downstream, grow in size initially, and then dissipate as the deposited solid reactants are depleted. However, in some cases, the heat accumulation is rapid and localized, leading to accelerated rise in the reactions rate and an accelerating process kinetics that resembles ignition in the combustion systems. These conditions, called run-away reactions, are unsafe and damaging to the system and need to be avoided by a proper system design and operating conditions.

The process model developed in this study is a useful tool for predicting the critical run-away conditions for a predefined system configuration and operating conditions. The results show that the most critical system parameters that affect the occurrence of these energetic events are those dealing with the reaction and process dynamic. Among those are concentrations of the gas and the deposited reactants, incoming gas temperature, and reactions kinetics (primarily the reaction activation energy). Flow conditions and thermodynamic properties of the reaction (such as the heat of reaction) have a much lower effect compared to the kinetic properties. These results are useful in implementing changes to mitigate the damaging run-away reactions.

\section{Conflicts of Interest}

The authors declare no conflicts of interest regarding the publication of this paper.

\section{References}

[1] Hu, C.M. (2010) Modern Semiconductor Devices for Integrated Circuits. Vol. 2, Prentice Hall, Upper Saddle River, NJ.

[2] Jones, A.C. and Hitchman, M.L. (2009) Chemical Vapour Deposition: Precursors, Processes and Applications. Royal Society of Chemistry.

[3] SRC-Sponsored Workshop on Energetic Reactions in Semiconductor Manufacturing Facilities; Deliverable Report 4236310, SRC Engineering Research Center, October 2018.

[4] Messham, R.L. and Tucker, W.K. (1986) Design of a Safe Facility for the Metalorganic Chemical Vapor Deposition of High-Purity GaAs and AlGaAs. Journal of Crystal Growth, 77, 101-107.

[5] Trammell, S., McIntyre, A. and Filipp, N. (2014) Environmental, Safety and Health Requirements for Use of Energetic Materials in Semiconductor R\&D and Manufacturing Processes. October 24, SEMATECH.

[6] Dzarnoski, J., et al. (1982) Shock-Induced Kinetics of the Disilane Decomposition and Silylene Reactions with Trimethylsilane and Butadiene. Organometallics, 1, 
1217-1220.

[7] Yoshida, K., et al. (2006) Thermal Decomposition Mechanism of Disilane. The Journal of Physical Chemistry A, 110, 4726-4731.

[8] Chen, J.R. (2002) Characteristics of Fire and Explosion in Semiconductor Fabrication Processes. Process Safety Progress, 21, 19-25.

[9] Chen, J.K.-C., et al. (2017) Ion Beam Assisted Organic Chemical Vapor Etch of Magnetic Thin Films. Journal of Vacuum Science \& Technology, 35, Article ID: 031304.

[10] Singh, V., et al. (2018) Dynamic Modeling and Performance Analysis of a Two-Fluid Molten-Salt Breeder Reactor System. Nuclear Technology, 202, 15-38. 


\section{Notations}

\begin{tabular}{|c|c|}
\hline$b$ & stoichiometry of deposit material \\
\hline$C_{a}$ & gas phase concentration, $\mathrm{mol} / \mathrm{m}^{3}$ \\
\hline$C_{20}$ & initial gas phase concentration, $\mathrm{mol} / \mathrm{m}^{3}$ \\
\hline$C_{b}$ & solid phase concentration, $\mathrm{mol} / \mathrm{m}^{2}$ \\
\hline$C_{b 0}$ & initial solid phase concentration, $\mathrm{mol} / \mathrm{m}^{2}$ \\
\hline$C_{b 0 \max }$ & peak initial solid phase concentration, $\mathrm{mol} / \mathrm{m}^{2}$ \\
\hline$C_{p g}$ & gas phase heat capacity, $\mathrm{J} / \mathrm{mol} \cdot \mathrm{K}$ \\
\hline$C_{p s}$ & solid phase heat capacity, $\mathrm{J} / \mathrm{mol} \cdot \mathrm{K}$ \\
\hline$D_{e}$ & dispersion coefficient, $\mathrm{m}^{2} / \mathrm{s}$ \\
\hline$d$ & diameter of the exhaust pipe \\
\hline$E$ & activation energy, $\mathrm{J} / \mathrm{mol}$ \\
\hline$h_{0}$ & heat transfer coefficient in the pipe, $\mathrm{J} / \mathrm{s} \cdot \mathrm{m}^{2} \cdot \mathrm{K}$ \\
\hline$h_{a}$ & outside heat transfer coefficient from pipe to ambient, $\mathrm{J} / \mathrm{s} \cdot \mathrm{m}^{2} \cdot \mathrm{K}$ \\
\hline$\Delta H$ & heat of reaction, $\mathrm{J} / \mathrm{mol}$ \\
\hline$k$ & reaction rate coefficient, $\mathrm{m}^{3 / \mathrm{mol} \cdot \mathrm{s}}$ \\
\hline$k_{0}$ & pre-exponential factor, $\mathrm{m}^{3 /} \mathrm{mol} \cdot \mathrm{s}$ \\
\hline$L$ & length of exhaust pipe, $\mathrm{m}$ \\
\hline$m$ & $1 / 4$ of the pipeline length, $\mathrm{m}$ \\
\hline$r$ & radius of exhaust pipe, $m$ \\
\hline$Q_{d}$ & heat dissipation, $\mathrm{J} / \mathrm{m}^{3}$ \\
\hline$Q_{a}$ & heat accumulation, $\mathrm{J} / \mathrm{m}^{3}$ \\
\hline$R$ & ideal gas constant, $\mathrm{J} / \mathrm{mol} \cdot \mathrm{K}$ \\
\hline$t$ & time, sec \\
\hline$T_{s}$ & solid phase temperature, $\mathrm{K}$ \\
\hline$T_{s 0}$ & initial solid temperature, $\mathrm{K}$ \\
\hline$T_{g}$ & gas phase temperature, $\mathrm{K}$ \\
\hline$T_{g 0}$ & initial gas phase temperature, $\mathrm{K}$ \\
\hline$T_{a}$ & ambient temperature, $\mathrm{K}$ \\
\hline$u_{0}$ & gas velocity, $\mathrm{m} / \mathrm{s}$ \\
\hline$z$ & distance along the pipe, $\mathrm{m}$ \\
\hline$\rho_{s}$ & density of solid phase, $\mathrm{mol} / \mathrm{m}^{3}$ \\
\hline$\rho_{g}$ & density of gas phase, $\mathrm{mol} / \mathrm{m}^{3}$ \\
\hline$\lambda_{e}$ & thermal conductivity of the gas phase, $\mathrm{W} / \mathrm{mol} \cdot \mathrm{K}$ \\
\hline
\end{tabular}

